Article

\title{
Effect of Process Control Parameters on the Filtration Performance of PAN-CTAB Nanofiber/Nanonet Web Combined with Meltblown Nonwoven
}

\author{
Hyo Kyoung Kang ${ }^{1,2}$, Hyun Ju Oh ${ }^{1}$ D, Jung Yeon Kim ${ }^{1}$, Hak Yong Kim ${ }^{2,3, *}$ and Yeong Og Choi ${ }^{1, *}$ \\ 1 Advanced Textile R\&D Department, Korea Institute of Industrial Technology, Ansan 15588, Korea; \\ hkkang@kitech.re.kr (H.K.K.); hjoh33@kitech.re.kr (H.J.O.); cobalt98@kitech.re.kr (J.Y.K.) \\ 2 Department of Organic Materials and Fiber Engineering, Jeonbuk National University, Jeonju 54896, Korea \\ 3 Department of Nano Convergence Engineering, Jeonbuk National University, Jeonju 54896, Korea \\ * Correspondence: dragon4875@gmail.com (H.Y.K.); yochoi@kitech.re.kr (Y.O.C.); \\ Tel.: +82-(0)63-270-2351 (H.Y.K.); +82-(0)31-8040-6084 (Y.O.C.)
}

check for

updates

Citation: Kang, H.K.; Oh, H.J.; Kim, J.Y.; Kim, H.Y.; Choi, Y.O. Effect of Process Control Parameters on the Filtration Performance of PAN-CTAB Nanofiber/Nanonet Web Combined with Meltblown Nonwoven. Polymers 2021, 13, 3591. https://doi.org/ $10.3390 /$ polym 13203591

Academic Editors: Ick-Soo Kim, Motahira Hashmi and Sana Ullah

Received: 14 September 2021

Accepted: 14 October 2021

Published: 19 October 2021

Publisher's Note: MDPI stays neutra with regard to jurisdictional claims in published maps and institutional affiliations.

Copyright: (c) 2021 by the authors. Licensee MDPI, Basel, Switzerland. This article is an open access article distributed under the terms and conditions of the Creative Commons Attribution (CC BY) license (https:/ / creativecommons.org/licenses/by/ $4.0 /)$.

\begin{abstract}
Nanofibers have potential applications as filters for particles with diameters $<10 \mu \mathrm{m}$ owing to their large specific surface area, macropores, and controllable geometry or diameter. The filtration efficiency can be increased by creating nanonets $(<50 \mathrm{~nm})$ whose diameter is smaller than that of nanofibers. This study investigates the effect of process conditions on the generation of nanonet structures from a polyacrylonitrile (PAN) solution containing cation surfactants; in addition, the filtration performance is analyzed. The applied electrospinning voltage and the electrostatic treatment of meltblown polypropylene (used as a substrate) are the most influential process parameters of nanonet formation. Electrospun polyacrylonitrile-cetylmethylammonium bromide (PAN-CTAB) showed a nanofiber/nanonet structure and improved thermal and mechanical properties compared with those of the electrospun PAN. The pore size distribution and filter efficiency of the PAN nanofiber web and PAN-CTAB nanofiber/nanonet web with meltblown were measured. The resulting PAN-CTAB nanofiber/nanonet air filter showed a high filtration efficiency of $99 \%$ and a low pressure drop of $7.7 \mathrm{mmH}_{2} \mathrm{O}$ at an air flow rate of $80 \mathrm{~L} / \mathrm{min}$. The process control methods for the nanonet structures studied herein provide a new approach for developing functional materials for air-filtration applications.
\end{abstract}

Keywords: nanonet; polyacrylonitrile; surfactant; electrospinning; meltblown; nanofiber/nanonet

\section{Introduction}

Air pollution threatens human health and the environment worldwide [1]. The manufacturing, transportation, and construction industries are some of the major contributors of air pollution as they release toxic waste and fine particles into the atmosphere [2,3]. High concentrations of particulate matter (PM) in the air are a primary cause of respiratory diseases [4-6]. PM, which consists of extremely small particles and liquid droplets [7], is classified into coarse $(2.5-10 \mu \mathrm{m}, \mathrm{PM} 10)$, fine $(0.1-2.5 \mu \mathrm{m}, \mathrm{PM} 2.5)$, and ultrafine $(<0.1 \mu \mathrm{m}$, PM0.1) PM [8]. In particular, PM2.5 can easily penetrate the human lungs and bronchi after a short period of exposure $[9,10]$. To prevent the inhalation or ingestion of PM2.5, researchers recommend the use of a mask filter for personal protection during outdoor activities; further, a window screen and purification filter should be used for indoor air quality protection.

Fibrous filters are generally commonly used for air filtration because they have a network support structure, can trap PM, and are made of tortuous pore channels for air transport [11]. In general, fibrous filters can be classified into meltblown (MB), spunbond, electrospun, and needle-punch filters [12]. Among them, conventional filters such as nonwoven needle-punch, glass-fiber, and spunbond filters have large fiber diameters and are suitable for use as coarse filters [13]. By contrast, meltblown filters and electrospun 
filters have small diameters and pores; therefore, they are used for fine particle filtration. MB nonwoven fabrics have a large surface area per unit weight and remarkable barrier properties, with a pore size of $0.5-10 \mu \mathrm{m}$ and an average diameter of 1-2 $\mu \mathrm{m}$ [14]. To increase the filtration efficiency, the fiber diameter must be decreased; however, there are limitations in the equipment design and process [15].

Electrospinning is a simple and versatile top-down spinning method capable of producing nano-to-submicron nonwoven filters from polymer and polymeric mixture solutions [16-18]. Electrospun nonwoven fabrics have a large surface area and porosity, making them significantly more effective in filtering out particles than their conventional counterparts $[19,20]$. In previous studies, we produced nano-sized nonwoven fabric filters by electrospinning various polymers, namely poly(vinyl alcohol) [21], poly(vinyl alcohol)/lignin [22], polystyrene [23], polyacrylonitrile (PAN) [24], polylmethylmethacrylate (PMMA) [24], polyethersulfone (PES) [25], polyurethane (PU) [26], and poly(lactic acid) [27]. The use of electrospinning for the fabrication of nano-sized nonwoven fabric filters improved the filtration performance over that of micrometer-sized nonwoven filters. Researchers have been conducting studies to further improve the efficiency of nanofiber filters $[1,28]$. To further reduce the diameter of electrospun nanofibers, electrospinning/net generation technology is being studied by controlling the process parameters. For instance, Shichao et al. [28] produced a PMIA nanofiber/net air filter with a filtration efficiency of $99.9 \%$ at a pressure drop of 92 Pa via electrospinning by mixing a surfactant with poly(m-phenylene isophthalamide). In addition, polyurethane (PU) was electrospun into a 20-nm-diameter nonwoven piece of fabric with a wide range of Steiner tree structures. An air filter with filtering efficiencies of $99 \%$ and $99.73 \%$ for PM1-0.5 and PM2.5-1, respectively, at a pressure drop of $28 \mathrm{~Pa}$ was fabricated [2]. The effect of collector type on net formation was also studied [29]. Hsiao et al. [30] added a surfactant to poly(vinylidene fluoride) to fabricate a nanofiber/nanonet and revealed that the filtration efficiency of the nonwoven fabric was $99.985 \%$ at $32 \mathrm{~L} / \mathrm{min}$ and the pressure drop was $66.7 \mathrm{~Pa}$. Furthermore, the effect of applied voltage on the formation of nanonets was studied. Several studies were conducted on air filters with nonwoven fabrics made of nanofibers/nanonets, and they achieved high efficiencies and low pressure drops.

PAN is a polar polymer that has a high dipole moment of 3.6 D; therefore, it can trap particulate pollutants in the air relatively easily [19,31]. In addition to a high filtration efficiency, it exhibits good ultraviolet resistance, weatherability, and chemical resistance [19]. PAN electrospun nanofiber membranes with these advantages are good materials for air filter media. As a related study, Lakshmanan et al. [32] produced an air filter media laminated with an electrospun web by adding a surfactant to the PAN solution. However, a nanonet structure was not observed. In fact, there are few studies related to the formation of nanonet structures in PAN polymers. Thus, there is substantial scope for manufacturing functional filter media by taking advantage of the characteristics of PAN and nanonets.

In this study, we investigated the formation conditions of nanonet structures in PAN nanofibers to obtain optimal filter media. The nanofiber-nanonet structure was achieved by controlling electrospinning process parameters such as the cationic additive, applied voltage, and electrostatically treated MB (e-MB) substrate (Figure 1). The morphology, thermal properties, and mechanical properties of the PAN nanofibers and PAN-CTAB nanofiber/nanonet web were analyzed. The pore size distribution and filter efficiency of PAN-CTAB/MB and pristine PAN/MB filter media were measured by varying the nanofiber basis weights. After fabricating a face mask using the PAN-CTAB nanofiber/nanonet web, the filtration efficiency and pressure drop were characterized under an increasing flow rate. 


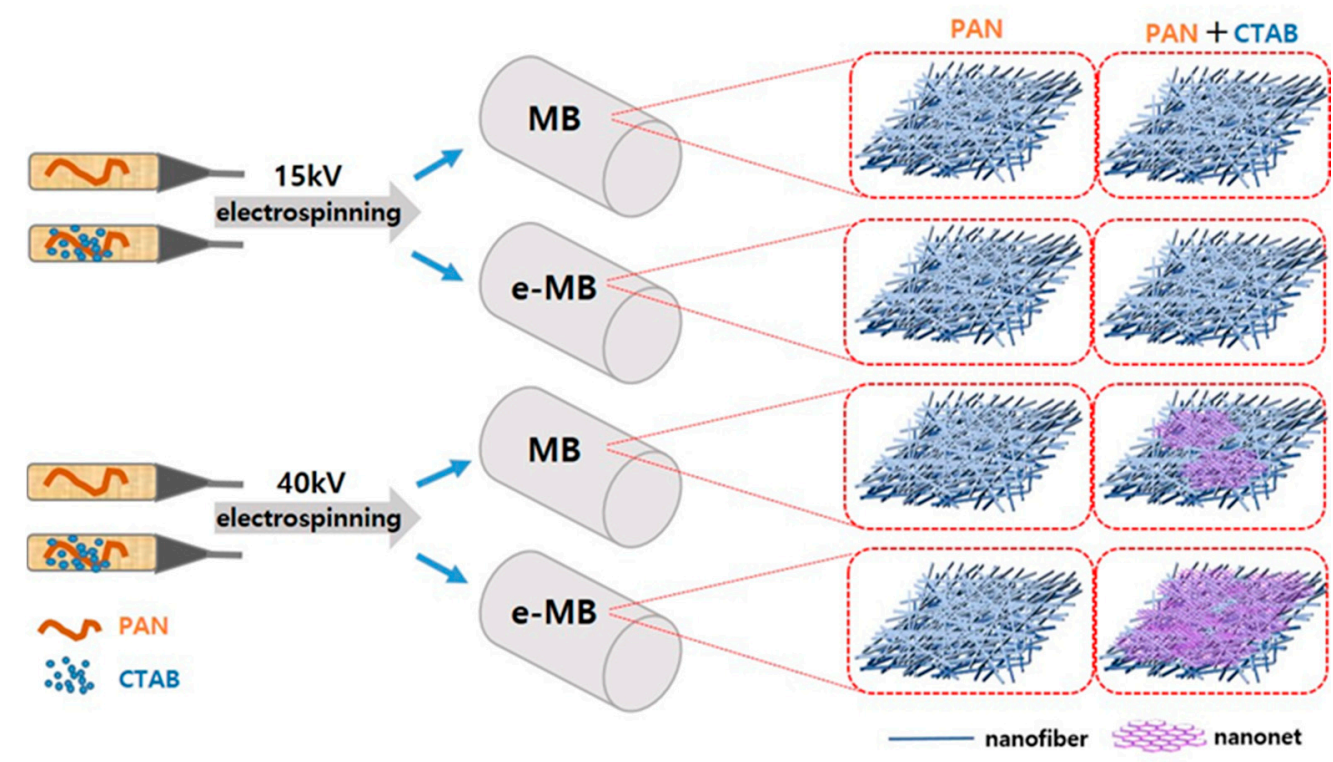

Figure 1. Schematic of the fabrication of PAN-CTAB nanofiber/nanonet web on electrostatically treated meltblown (e-MB) and discharged MB nonwoven filter.

\section{Materials and Methods}

\subsection{Materials}

Analytical-grade polyacrylonitrile (PAN, average $M w=150,000 \mathrm{~g} \mathrm{~mol}^{-1}$ ) was purchased from Sigma-Aldrich. Cetylmethylammonium bromide (CTAB), N,N-dimethyl formamide (DMF), and isopropyl alcohol (IPA) were obtained from Dae-Jung Chemical \& Metals Co., Ltd., Siheung, Korea. The e-MB material used as a substrate was provided by Cheong-Jung clean Co., Ltd., Jincheon, Korea. All chemicals were used without further treatment.

\subsection{Preparation of Filter Media}

The PAN solution was prepared by dissolving $1.739 \mathrm{~g}$ of PAN in $20 \mathrm{~mL}$ of DMF and stirring for $10 \mathrm{~h}$ at $26^{\circ} \mathrm{C}$. The PAN-CTAB solution was prepared by adding $1.3 \mathrm{wt} \%$ of CTAB powder to the PAN solution and stirred for $12 \mathrm{~h}$ to form electrospinning solutions with increased conductivity [33]. Thus, two batches of solutions were prepared, PAN and PAN-CTAB. Subsequently, the solutions were poured into a 23-gauge syringe connected to a metal nozzle. The e-MB and discharged MB materials were used as substrates by sticking them on a drum collector. The e-MB material was immersed in IPA for $20 \mathrm{~min}$, and then dried at room temperature for $24 \mathrm{~h}$ to nullify its electrostatic force. The electrospinning process conditions were as follows: the distance between the spinneret and the nonwoven substrates was $15 \mathrm{~cm}$, the applied voltage from the power supply was 15 and $40 \mathrm{kV}$, the feed rate of the spinning solution was $5 \mu \mathrm{L} / \mathrm{min}$, and the relative humidity (RH) and temperature were $40 \% \pm 5 \%$, and $22 \pm 2{ }^{\circ} \mathrm{C}$, respectively. Finally, the nanofiber web was dried in an oven at $100{ }^{\circ} \mathrm{C}$ for $2 \mathrm{~h}$ to evaporate the residual solvent.

\subsection{Characterization of Nanofiber/Nanonet Web}

The morphological characteristics of the PAN nanofiber web and PAN-CTAB nanofiber/ nanonet web obtained with different voltages and substrates were investigated by fieldemission scanning electron microscopy (FE-SEM, SU8010, Hitachi Co., Tokyo, Japan) at an acceleration voltage of $10 \mathrm{kV}$. The thermal properties of the two webs were analyzed by thermogravimetry (TGA, Q500, TA Instruments Co., New Castle, DE, USA) in an $\mathrm{N}_{2}$ atmosphere with a heating rate of $10{ }^{\circ} \mathrm{C} / \mathrm{min}$. The thermal behaviors were examined by differential scanning calorimetry (DSC, 404 C, Netzsch Co., Selb, Germany) from 30 to $350{ }^{\circ} \mathrm{C}$ with a heating rate of $10{ }^{\circ} \mathrm{C} / \mathrm{min}$ under an $\mathrm{N}_{2}$ atmosphere. The crystal formation and structural characteristics due to the addition of CTAB were analyzed by $X$-ray diffrac- 
tion (XRD, X'PERT-PRO Powder, PANalytical Co., Almelo, The Netherlands). The X-rays were generated at $40 \mathrm{kV}$ and $30 \mathrm{~mA}$ with $\mathrm{Cu}-\mathrm{Ka}$ radiation (wavelength, $\lambda=0.154 \mathrm{~nm}$ ). The scan speed and measuring range were $4^{\circ} / \mathrm{min}$ and $10^{\circ}-60^{\circ}$, respectively. The structural characteristics of the two types of webs were analyzed by Fourier transform infrared spectroscopy (FT-IR spectrometer, Nicolet NEXUS, Thermo Fisher Scientific Co., Waltham, MA, USA) using the ATR mode in the scan range of $400-4000 \mathrm{~cm}^{-1}$. The mechanical properties with and without $\mathrm{CTAB}$ were determined using a universal testing machine (Instron3343, Instron Co., Barcelona, Spain) equipped with a $50 \mathrm{~N}$ load cell. At least 10 rectangular web specimens $(50 \mathrm{~mm} \times 100 \mathrm{~mm}$ ) were stretched at a constant crosshead speed of $10 \mathrm{~mm} / \mathrm{min}$ and tested.

\subsection{Analysis of Filter Media}

The pore-size distributions and mean pore diameters of the PAN and PAN-CTAB filter media samples were measured by capillary flow porometry (CFP, CFO-1500AEX, Porous Materials Inc., Ithaca, NY, USA). All the samples were cut into $3 \mathrm{~cm} \times 3 \mathrm{~cm}$ squares. Galwick with a surface tension of 20.1 dynes/cm was used as the wetting agent. Maximum volumetric flow rates of 20,000 and 100,000 L/m were used in the air permeability and pore distribution tests. The filtration performance of the media with the MB nonwoven material was tested using an automated filter tester (TSI 8130, TSI Instruments Co. Ltd., Shoreview, MN, USA). $\mathrm{NaCl}$ aerosols with a mass median diameter of $0.26 \mathrm{~mm}$ were produced using an atomizing air pump. The aerosol particles permeated the sample at a flow rate of $32 \mathrm{~L} / \mathrm{min}$. The filter media had an effective test area of $100 \mathrm{~cm}^{2}$. A mask was fabricated by adding spunbond nonwoven fabrics, which did not affect the filtering efficiency of the samples electrospun on the MB nonwoven fabrics. The size of mask sample was a width of $18 \mathrm{~cm}$ and a height of $17 \mathrm{~cm}$, and the result was obtained by folding the middle part thrice. The filtering performance was tested with different air volumetric flow rates $(10-80 \mathrm{~L} / \mathrm{min})$. Each sample was tested five times to ensure accuracy.

\section{Results and Discussion}

A nanofiber filter media with nanonet structures was manufactured to improve its ability to filter ultrafine particles. To manufacture the PAN nanofiber web with nanonet structures, the effects of an ionic surfactant and spinning conditions were confirmed. Figure 2 illustrates the FE-SEM images of the PAN nanofiber web surface prepared according to the surfactant, substrate conditions (charged and uncharged MB substrates), and spinning voltages ( 15 and $40 \mathrm{kV}$ ). Figure $2 \mathrm{a}-\mathrm{d}$ shows the surface images of the pristine PAN nanofiber web according to the manufacturing conditions. The formation of a nanonet under the applied voltage and substrate conditions was not observed. Figure 2e-f depicts the surface images of the PAN-CTAB nanofiber web or nanofiber/nanonet web prepared by adding $C T A B$ as the surfactant. A nanonet was observed at an applied voltage $\geq 40 \mathrm{kV}$. The PAN-CTAB nanofiber/nanonet web spun on the e-MB substrate (Figure $2 \mathrm{~h}$ ) had a larger nanonet than that of the web spun on the discharged MB substrate. This result led to the conclusion that the ions in the e-MB substrate influence the nanonet production under high-voltage conditions $(40 \mathrm{kV})$. The pristine PAN nanofiber web had an average diameter of $245.3 \mathrm{~nm}$. 

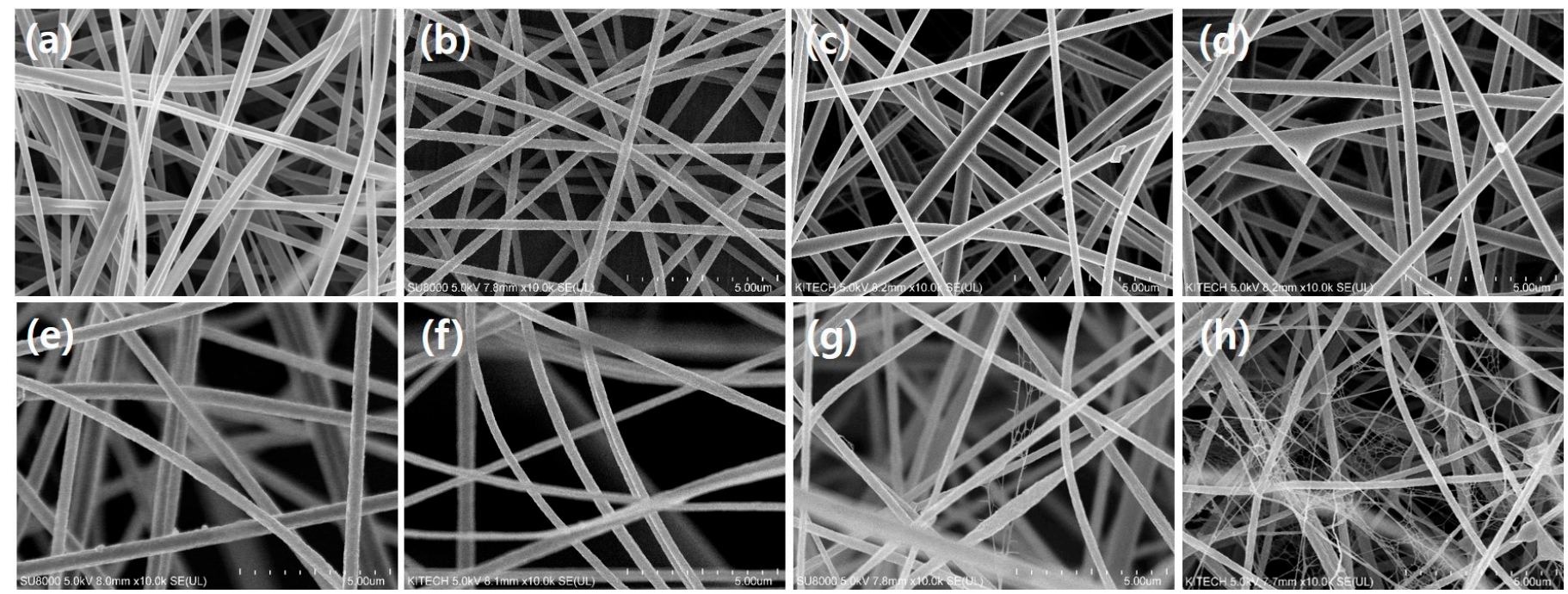

Figure 2. Field-emission scanning electron microscopy (FE-SEM) images of PAN (a-d) and PAN-CTAB (e-h) nanofiber/(nanonet) web with varying spinning voltage and substrate type: (a,e) $15 \mathrm{kV}$, meltblown (MB), (b,f) $15 \mathrm{kV}$, e-MB, (c,g) $40 \mathrm{kV}, \mathrm{MB}$, and (d,g) $40 \mathrm{kV}, \mathrm{e}-\mathrm{MB}$.

The average diameter of the PAN-CTAB nanofiber/nanonet web (Figure $2 \mathrm{~h}$ ) was $276.1 \mathrm{~nm} / 26.1 \mathrm{~nm}$. The addition of CTAB increased the diameter of the PAN nanofibers compared to that in the PAN nanofiber web.

TGA and DSC were performed to evaluate the effect of the thermal properties of CTAB on the PAN-CTAB nanofiber/nanonet web. The results of the TGA are illustrated in Figure 3a. The two types of nanofibers and CTAB powder obtained under each of the conditions began to decompose at $300.9,229.18$, and $284.81^{\circ} \mathrm{C}$. It was confirmed that the addition of CTAB lowered the temperature of thermal decomposition of the PANCTAB nanofiber/nanonet web. The DSC analysis confirmed the effect of CTAB powder on the thermal properties of the PAN nanofiber web. In general, the PAN nanofiber web generates exothermic peaks owing to cyclization, dehydration, and oxidation reactions at 200-350 ${ }^{\circ} \mathrm{C}$ [33]. During the DSC analysis, the $\mathrm{C} \equiv \mathrm{N}$ bonds were converted to $\mathrm{C}=\mathrm{N}$ bonds with the stabilization process [34]. The exothermic peaks of the PAN nanofiber web and PAN-CTAB nanofiber/nanonet web were confirmed at 295 and $300.2^{\circ} \mathrm{C}$, respectively (Figure $3 \mathrm{~b}$ ). The endothermic peak of the $\mathrm{CTAB}$ powder appeared at approximately $102^{\circ} \mathrm{C}$, and the presence of CTAB was confirmed by the occurrence of an endothermic peak at the same temperature in the PAN-CTAB nanofiber/nanonet web. The onset temperature of the PAN nanofiber web increased by approximately $5{ }^{\circ} \mathrm{C}$ with the addition of CTAB. $\mathrm{CTAB}$ acted as an inhibitor to retard the cyclization reaction of PAN in the PAN-CTAB nanofiber/nanonet web, and blocked the recombination reaction by reducing the freeradical formation rate of the nitrile group [34]. 

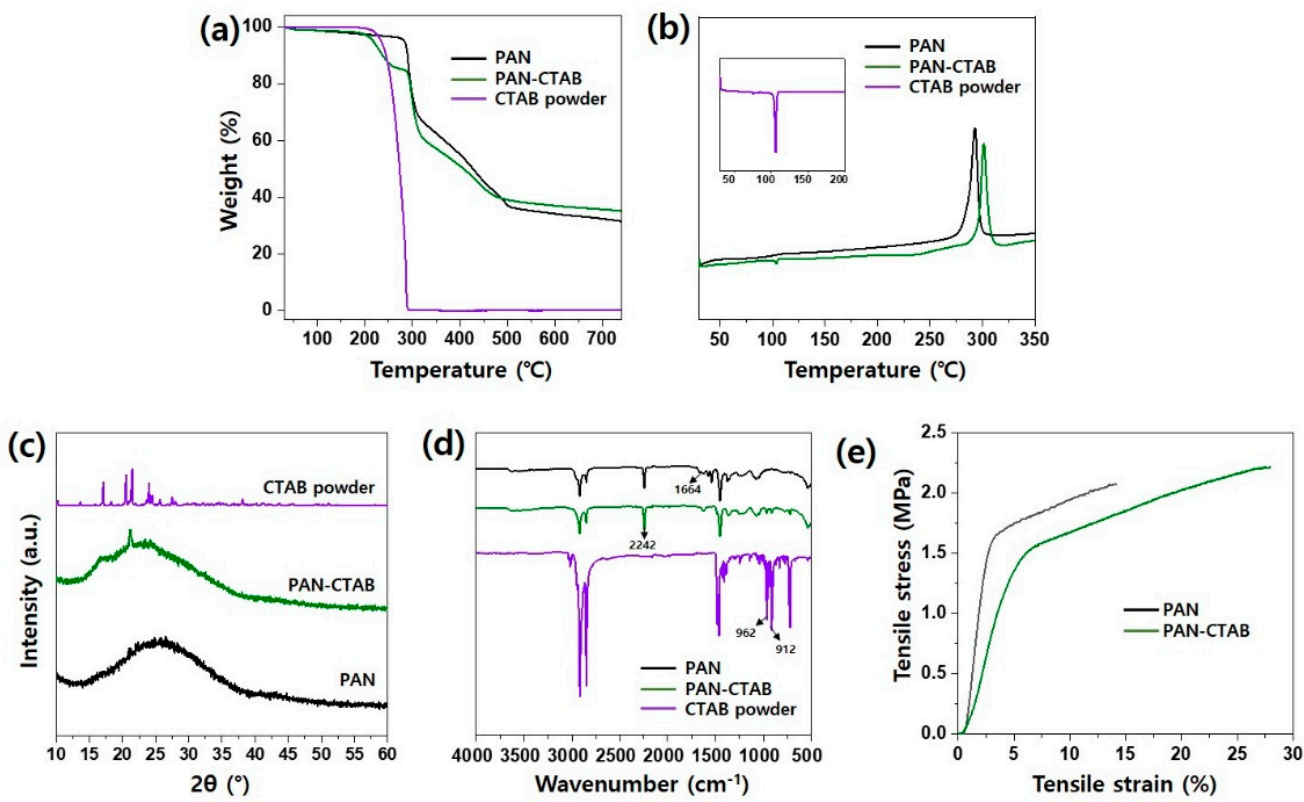

Figure 3. Characterizations of PAN nanofiber web, PAN-CTAB nanofiber/nanonet web, and CTAB powder. (a) Thermogravimetric analysis (TGA), (b) differential scanning calorimetry (DSC), (c) X-ray diffraction (XRD) patterns, and (d) Fourier transform infrared (FT-IR) spectra results of the three groups, respectively. (e) S-S curves of the PAN nanofiber and PAN-CTAB nanofiber/nanonet web.

Figure $3 \mathrm{c}$ shows the XRD patterns of the pristine PAN nanofiber web, PAN-CTAB nanofiber/nanonet web, and CTAB powder. The PAN nanofiber web displayed a broad crystal peak at $25.7^{\circ}$. The crystal peak of the $\mathrm{CTAB}$ powder exhibited high intensities at $17.3,20.4,21.4$, and $24.3^{\circ}$. The PAN-CTAB nanofiber/nanonet web showed a broad peak at approximately $17-25^{\circ}$ under the influence of CTAB. It is plausible that the addition of the CTAB powder enlarged the PAN nanofiber web crystals.

Figure $3 \mathrm{~d}$ displays the FT-IR spectrum of the pristine PAN nanofiber web, CTAB powder, and PAN/CTAB nanofiber/nanonet web. The spectrum corresponding to the pristine CTAB exhibits the characteristic absorption bands of the CTAB functional groups, as reported previously [6]. The absorption bands between 2960 and 2820 and 1510 and $1440 \mathrm{~cm}^{-1}$ correspond to $-\mathrm{CH}_{2}-$ stretching and $-\mathrm{CH}_{2}-$ bending in CATB and the PAN$\mathrm{CTAB}$ nanofiber/nanonet web, respectively, confirming the presence of long alkyl groups of CTAB in the PAN-CTAB nanofiber/nanonet web [35]. The pristine PAN nanofiber web exhibited prominent peaks at 1452, 1664, 2240, and $2923 \mathrm{~cm}^{-1}$. The peaks at 1664 , 2240 , and $2923 \mathrm{~cm}^{-1}$ represent the stretching vibrations of $-\mathrm{C}=\mathrm{N},-\mathrm{C} \equiv \mathrm{N}$, and $-\mathrm{CH}$ groups, respectively, whereas that at $1452 \mathrm{~cm}^{-1}$ represents the bending vibration of the $-\mathrm{CH}_{2}$ group. A subtle increase in the characteristic peak of the PAN nanofiber web was observed at $1664 \mathrm{~cm}^{-1}$ with the addition of CTAB in the PAN nanofiber web.

Figure 3e summarizes the mechanical properties of the pristine PAN nanofiber web and PAN-CTAB nanofiber/nanonet web. The tensile strengths of the two webs were approximately 2.07 and $2.27 \mathrm{MPa}$, respectively. The tensile strength of the PAN-CTAB nanofiber/nanonet web improved by approximately $110 \%$ with the addition of the CTAB powder over that of the pristine web. The elongation of the PAN-CTAB nanofiber nanonet web also improved by approximately $200 \%$ compared with that of the pristine PAN nanofiber web. Notably, the tensile strain nearly doubled because the nanonet was distributed between nanofibers and served as a reinforcement in the cross-sectional direction [2].

Figure $4 \mathrm{a}, \mathrm{b}$ shows the pore-size distribution of the filter media fabricated by laminating the PAN nanofiber web and PAN-CTAB nanofiber/nanonet web by weight $\left(0.6-2.4 \mathrm{~g} / \mathrm{m}^{2}\right)$ on the MB substrate. As the weight of the nanofiber web increases, leading to thickening of the nanofibers, the average pore size decreases as the pores are gradually blocked. In 
addition, in the case of the PAN-CTAB filter media with the net structure, the pore-size distribution was confirmed to be narrower than that of the PAN filter media owing to nanonet generation. The inset graph, an enlargement of the region corresponding to $<10 \mu \mathrm{m}$ diameter in the original graph, shows that the smallest pore size is attained at 0.9 $\mathrm{g} / \mathrm{m}^{2}$ in the case of the PAN-CTAB nanofiber/nanonet web.

(a)

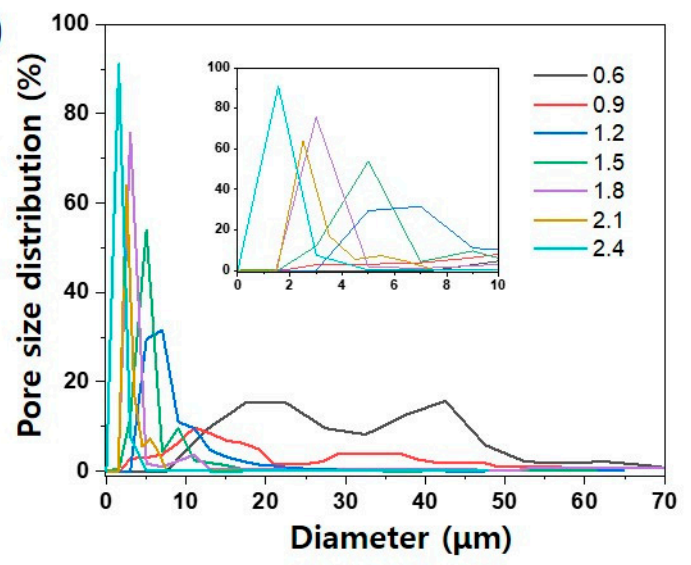

(b)

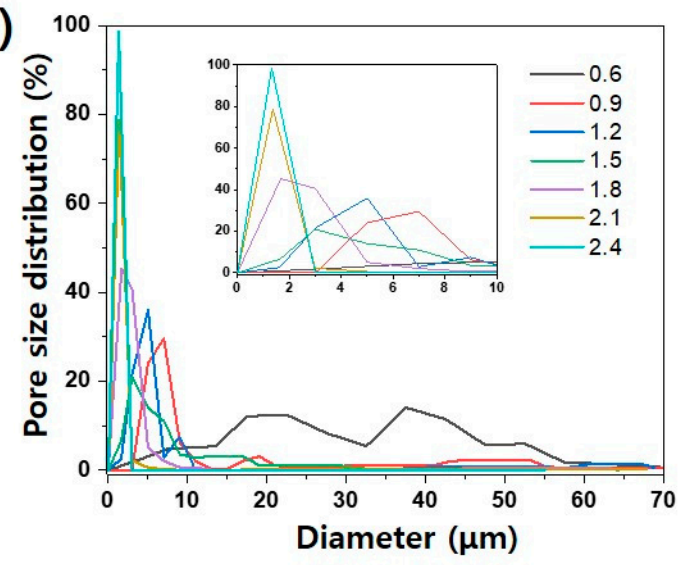

Figure 4. Pore-size distribution of (a) PAN and (b) PAN-CTAB filter media with varying base weight of the electrospun web.

Despite its high efficiency, the application of a nanofiber filter as a mask is limited by its high breathing resistance. The filtration efficiency was evaluated because it was affected by the formation of the nanonet structure in the nanofiber. Figure 5 a shows the filtering efficiency according to the nanofiber weight. The control MB group without nanofibers had a filtering efficiency of $53.8 \%$, and the filter media laminated with the PAN nanofiber web had an increased filtration efficiency of $72.4-88.7 \%$ as the weight of the nanofiber increased to $0.3-2.4 \mathrm{~g} / \mathrm{m}^{2}$. The efficiency of the filter media with stacked PAN-CTAB nanofiber/nanonet webs also improved to $74.9-99 \%$. As the filter efficiency increased, the pressure drop also increased to 0.489 (only MB) up to $3.2 \mathrm{mmH}_{2} \mathrm{O}$ for the media laminated with the PAN nanofiber web, and to 0.489 (only MB) up to $3.7 \mathrm{mmH}_{2} \mathrm{O}$ for the media laminated with the PAN-CTAB nanofiber/nanonet web. Based on these results, the quality factor $(\mathrm{QF}=-\ln (1-\eta) / \Delta \mathrm{p}$, where $\eta$ is the filtration efficiency, and $\Delta \mathrm{p}$ is the pressure drop) was calculated to evaluate the comprehensive filtering performance [36].

The QF is an indicator of the filtering efficiency considered for the pressure drop in the filter media. The filter in which the PAN-CTAB nanofiber/nanonet web was stacked from $0.9 \mathrm{~g} / \mathrm{m}^{2}$ or higher by weight of the laminated nanofiber had a significantly higher QF. The SEM images in Figure 5d,e confirm $\mathrm{NaCl}$ aerosol capture on the nanofiber after the filtration test. A notably larger amount of $\mathrm{NaCl}$ was adsorbed to the filter media in which the PAN-CTAB nanofiber/nanonet web was laminated than that on which the pristine PAN nanofiber web was laminated. This is because its ability to trap particles was improved by the presence of the nanonet between large pores. 

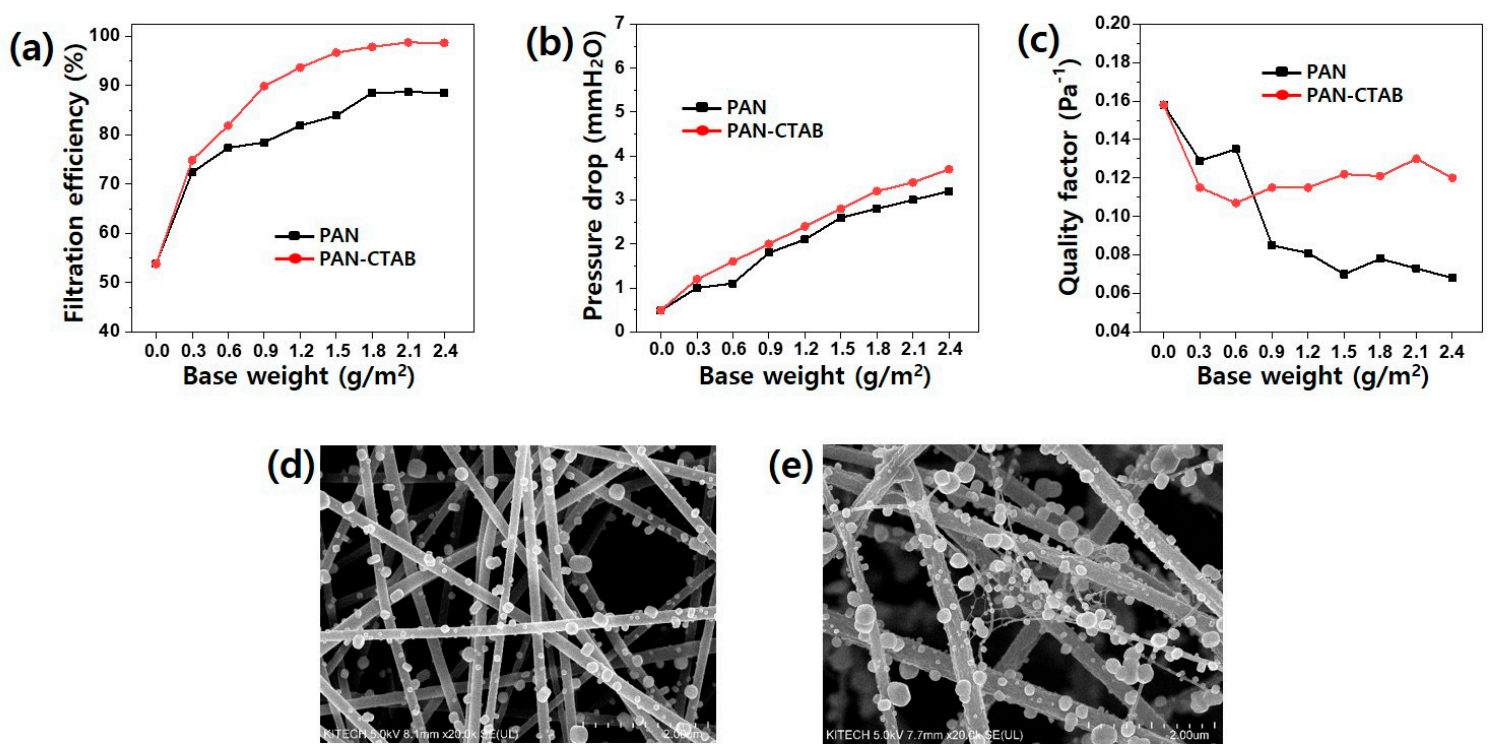

Figure 5. (a) Filtration efficiency, (b) pressure drop, and (c) quality factor of the PAN and PAN-CTAB filter media for different base weights of the electrospun web. The SEM images of (d) PAN nanofiber and (e) PAN-CTAB filter media after five iterations of the TSI8130 filtration evaluation test.

A mask prototype was fabricated with a PAN-CTAB nanofiber/nanonet web-layered sample of $2.1 \mathrm{~g} / \mathrm{m}^{2}$, which had the highest $\mathrm{QF}$ value $\left(0.13 \mathrm{~Pa}^{-1}\right)$ among the filter media. As shown in the schematic diagram of Figure 6a, the mask was prepared by adding spunbond nonwoven fabric on both sides of the sample, which did not affect the filtering efficiency (Figure 6b). The filtering efficiency was tested with various flow rates. Consequently, the pressure drop across the layers of the mask gradually increased at high flow rates, and the efficiency was maintained at $98.5-99 \%$. When the flow rate reached $80 \mathrm{~L} / \mathrm{min}$, the pressure drop was only $7.7 \mathrm{mmH}_{2} \mathrm{O}$, which indicates high efficiency.

(a)

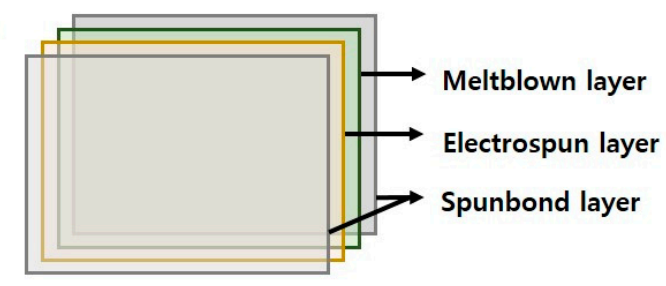

(b)

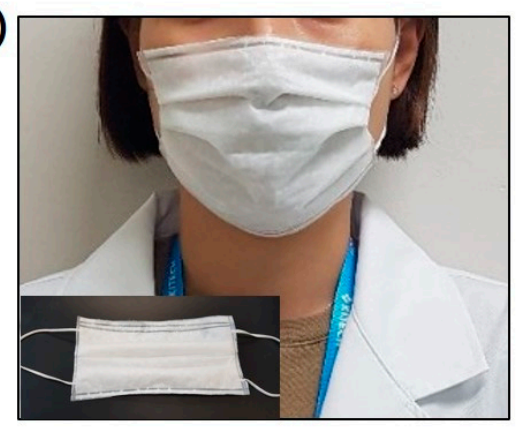

(c)

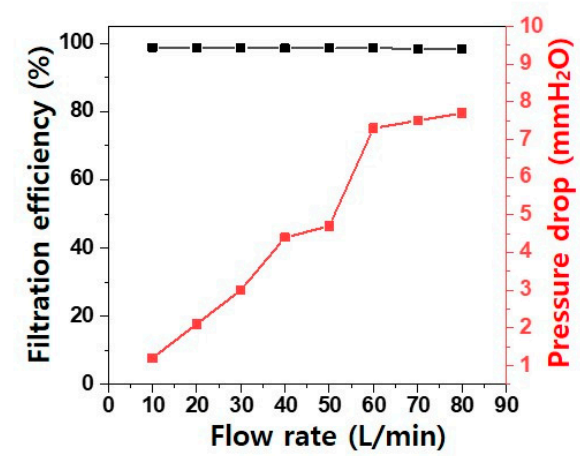

Figure 6. Schematic diagram of the structure of the filter media (a). A photograph of a person wearing the fabricated mask (b). Filtration performance evaluation by flow rate (c). 


\section{Conclusions}

PAN-CTAB filter media containing a nanofiber/nanonet web were prepared using a cationic surfactant to increase the ion mobility via electrospinning at a high voltage. A larger nanonet was formed on an MB nonwoven substrate when the applied electrospinning voltage was $40 \mathrm{kV}$. The residual amount at $750{ }^{\circ} \mathrm{C}$ was found to be $4.5 \%$ more than that of the PAN-CTAB nanofiber/nanonet web. The DSC results showed that the addition of CTAB improved the thermal properties of the web as the exothermic peak temperatures increased by $5{ }^{\circ} \mathrm{C}$. In the sample with the nanonet formed by the addition of CTAB, application of high voltage $(40 \mathrm{kV})$, and use of the e-MB substrate, the nanofiber diameter increased; in addition, the tensile strength and tensile strain increased by $110 \%$ and $200 \%$, respectively. The filtration efficiencies of the PAN (nanofiber web laminated on MB) and PAN-CTAB filter media were $88.7 \%$ and $99 \%$, respectively, at the largest weight (nanofiber/nanonet web). The sample with the highest QF $\left(0.13 \mathrm{~Pa}^{-1}\right)$ among the filter media was a 2.1 $\mathrm{g} / \mathrm{m}^{2}$ stack of PAN-CTAB nanofiber/nanonet web. A high efficiency, low-pressure-drop $\left(3.4 \mathrm{mmH}_{2} \mathrm{O}\right)$ filter, with a filtration efficiency of $99 \%$, was achieved. For application in a face mask, the uniformity of human inhalation and exhalation was considered, and a high filtration efficiency was measured at a high flow rate $(80 \mathrm{~L} / \mathrm{min})$. The PAN-CTAB filter media have markedly improved properties compared to those of the PAN filter media of the control groups. In summary, the specifications of the PAN nanofiber/nanonet web can be altered by controlling the process parameters.

Author Contributions: Conceptualization, H.K.K., H.Y.K. and Y.O.C.; methodology and investigation, H.K.K. and H.J.O.; formal analysis, H.K.K., J.Y.K. and H.J.O.; writing-original draft preparation, H.K.K., J.Y.K. and H.J.O.; writing-review and editing, H.K.K., H.J.O., H.Y.K. and Y.O.C.; supervision, H.Y.K. and Y.O.C.; project administration, H.K.K., J.Y.K. and Y.O.C.; funding acquisition, Y.O.C. All authors have read and agreed to the published version of the manuscript.

Funding: This research was funded by the Korea Institute of Industrial Technology, grant number EH210009.

Institutional Review Board Statement: Not applicable.

Informed Consent Statement: Not applicable.

Data Availability Statement: Not applicable.

Conflicts of Interest: The authors declare no conflict of interest.

\section{References}

1. Zhu, M.; Han, J.; Wang, F.; Shao, W.; Xiong, R.; Zhang, Q.; Pan, H.; Yang, Y.; Samal, S.K.; Zhang, F.; et al. Electrospun nanofibers membranes for effective air filtration. Macromol. Mater. Eng. 2017, 302, 1-27. [CrossRef]

2. Zuo, F.; Zhang, S.; Liu, H.; Fong, H.; Yin, X.; Yu, J.; Ding, B. Free-standing polyurethane nanofiber/nets air filters for effective PM capture. Small 2017, 13, 1702139. [CrossRef]

3. Brook, R.D.; Rajagopalan, S.; Pope, C.A.; Brook, J.R.; Bhatnagar, A.; Diez-Roux, A.V.; Holguin, F.; Hong, Y.; Luepker, R.V.; Mittleman, M.A.; et al. Particulate matter air pollution and cardiovascular disease: An update to the scientific statement from the american heart association. Circulation 2010, 121, 2331-2378. [CrossRef]

4. Heft-Neal, S.; Burney, J.; Bendavid, E.; Burke, M. Robust relationship between air quality and infant mortality in Africa. Nature 2018, 559, 254-258. [CrossRef]

5. Zhang, Q.; Jiang, X.; Tong, D.; Davis, S.J.; Zhao, H.; Geng, G.; Feng, T.; Zheng, B.; Lu, Z.; Streets, D.G.; et al. Transboundary health impacts of transported global air pollution and international trade. Nature 2017, 543, 705-709. [CrossRef]

6. Dockery, D.W.; Pope, C.A.; Xu, X.; Spengler, J.D.; Ware, J.H.; Fay, M.E.; Benjamin, G.; Ferris, J.; Speizer, F.E. An association between air pollution and mortality in six U.S. cities. N. Engl. J. Med. 1993, 29, 1753-1759. [CrossRef]

7. Wang, X.; Xiang, H.; Song, C.; Zhu, D.; Sui, J.; Liu, Q.; Long, Y. Highly efficient transparent air filter prepared by collectingelectrode-free bipolar electrospinning apparatus. J. Hazard. Mater. 2020, 385, 121535. [CrossRef] [PubMed]

8. Senlin, L.; Zhenkun, Y.; Xiaohui, C.; Minghong, W.; Guoying, S.; Jiamo, F.; Paul, D. The relationship between physicochemical characterization and the potential toxicity of fine particulates $\left(\mathrm{PM}_{2.5}\right)$ in Shanghai atmosphere. Atmos. Environ. 2008, 42, 7205-7214. [CrossRef]

9. Shi, Y.; Ji, Y.; Sun, H.; Hui, F.; Hu, J.; Wu, Y.; Fang, J.; Lin, H.; Wang, J.; Duan, H.; et al. Nanoscale characterization of PM 2.5 airborne pollutants reveals high adhesiveness and aggregation capability of soot particles. Sci. Rep. 2015, 5, 1-10. [CrossRef] 
10. Zhang, L.; Jin, X.; Johnson, A.C.; Giesy, J.P. Hazard posed by metals and As in PM2.5 in air of five megacities in the Beijing-TianjinHebei region of China during APEC. Environ. Sci. Pollut. Res. 2016, 23, 17603-17612. [CrossRef] [PubMed]

11. Barhate, R.S.; Ramakrishna, S. Nanofibrous filtering media: Filtration problems and solutions from tiny materials. J. Memb. Sci. 2007, 296, 1-8. [CrossRef]

12. Zhang, H.; Liu, J.; Zhang, X.; Huang, C.; Jin, X. Design of electret polypropylene melt blown air filtration material containing nucleating agent for effective PM2.5 capture. RSC Adv. 2018, 8, 7932-7941. [CrossRef]

13. Zhang, H.; Liu, J.; Zhang, X.; Huang, C.; Zhang, Y.; Fu, Y.; Jin, X. Design of three-dimensional gradient nonwoven composites with robust dust holding capacity for air filtration. J. Appl. Polym. Sci. 2019, 136, 47827. [CrossRef]

14. Kim, H.J.; Han, S.W.; Joshi, M.K.; Kim, C.S. Fabrication and characterization of silver nanoparticle-incorporated bilayer electrospunmelt-blown micro/nanofibrous membrane. Int. J. Polym. Mater. Polym. Biomater. 2017, 66, 514-520. [CrossRef]

15. Dutton, K.C. Overview and analysis of the meltblown process and parameters. J. Text. Apparel. Technol. Manag. 2008, 6, 1-24.

16. Joshi, M.K.; Tiwari, A.P.; Pant, H.R.; Shrestha, B.K.; Kim, H.J.; Park, C.H.; Kim, C.S. In situ generation of cellulose nanocrystals in polycaprolactone nanofibers: Effects on crystallinity, mechanical strength, biocompatibility, and biomimetic mineralization. ACS Appl. Mater. Interfaces 2015, 7, 19672-19683. [CrossRef]

17. Fibers, N.; Bognitzki, B.M.; Czado, W.; Frese, T.; Schaper, A.; Hellwig, M.; Steinhart, M.; Greiner, A.; Wendorff, J.H. Nanostructured fibers via electrospinning **. Adv. Mater. 2001, 13, 70-72. [CrossRef]

18. Long, Y.; Li, M.; Gu, C.; Wan, M.; Duvail, J.; Liu, Z.; Fan, Z. Progress in Polymer Science Recent advances in synthesis, physical properties and applications of conducting polymer nanotubes and nanofibers. Prog. Polym. Sci. 2011, 36, 1415-1442. [CrossRef]

19. Liu, C.; Hsu, P.; Lee, H.; Ye, M.; Zheng, G.; Liu, N.; Li, W.; Cui, Y. Transparent air filter for high-efficiency $\mathrm{PM}_{2.5}$ capture. Nat. Commun. 2015, 6, 6205. [CrossRef]

20. Kaur, S.; Sundarrajan, S.; Rana, D.; Matsuura, T.; Ramakrishna, S. Influence of electrospun fiber size on the separation efficiency of thin film nanofiltration composite membrane. J. Memb. Sci. 2012, 392-393, 101-111. [CrossRef]

21. Qin, X.; Wang, S. Electrospun nanofibers from crosslinked poly(vinyl alcohol) and its filtration efficiency. J. Appl. Polym. Sci. 2008, 109, 951-956. [CrossRef]

22. Cui, J.; Lu, T.; Li, F.; Wang, Y.; Lei, J.; Ma, W.; Zou, Y.; Huang, C. Flexible and transparent composite nanofiber membrane that was fabricated via a "green" electrospinning method for efficient particulate matter 2.5 capture. J. Colloid Interface Sci. 2021, 582, 506-514. [CrossRef] [PubMed]

23. Lin, T.; Wang, H.; Wang, H.; Wang, X. The charge effect of cationic surfactants on the elimination of fibre beads in the electrospinning of polystyrene. Nanotechnology 2004, 15, 1375-1381. [CrossRef]

24. Myoung, K.; Bagus, A.; Iskandar, F.; Bao, L.; Niinuma, H.; Okuyama, K. Morphology optimization of polymer nanofiber for applications in aerosol particle filtration. Sep. Purif. Technol. 2010, 75, 340-345. [CrossRef]

25. Sambaer, W.; Zatloukal, M.; Kimmer, D. 3D modeling of filtration process via polyurethane nanofiber based nonwoven filters prepared by electrospinning process. Chem. Eng. Sci. 2011, 66, 613-623. [CrossRef]

26. Wang, Z.; Pan, Z. Preparation of hierarchical structured nano-sized/porous poly(lactic acid) composite fibrous membranes for air filtration. Appl. Surf. Sci. 2015, 356, 1168-1179. [CrossRef]

27. Greiner, A.; Wendorff, J.H. Electrospinning: A fascinating method for the preparation of ultrathin fibers. Angew. Chem.-Int. Ed. 2007, 46, 5670-5703. [CrossRef]

28. Zhang, S.; Liu, H.; Yin, X.; Li, Z.; Yu, J.; Ding, B. Tailoring mechanically robust poly(m-phenylene isophthalamide) nanofiber/nets for ultrathin high-efficiency air filter. Sci. Rep. 2017, 7, 40550. [CrossRef]

29. Zhang, S.; Liu, H.; Tang, N.; Ge, J.; Yu, J.; Ding, B. Direct electronetting of high-performance membranes based on self-assembled 2D nanoarchitectured networks. Nat. Commun. 2019, 10, 1458. [CrossRef]

30. Li, X.; Wang, C.; Huang, X.; Zhang, T.; Wang, X.; Min, M.; Wang, L.; Huang, H.; Hsiao, B.S. Anionic surfactant-triggered steiner geometrical poly(vinylidene fluoride) nanofiber/nanonet air filter for efficient particulate matter removal. ACS Appl. Mater. Interfaces 2018, 10, 42891-42904. [CrossRef]

31. Su, J.; Yang, G.; Cheng, C.; Huang, C.; Xu, H.; Ke, Q. Hierarchically structured $\mathrm{TiO}_{2} / \mathrm{PAN}$ nanofibrous membranes for highefficiency air filtration and toluene degradation. J. Colloid Interface Sci. 2017, 507, 386-396. [CrossRef]

32. Lakshmanan, A.; Gavali, D.S.; Thapa, R.; Sarkar, D. Synthesis of CTAB-Functionalized Large-Scale Nanofibers Air Filter Media for Efficient PM2.5Capture Capacity with Low Airflow Resistance. ACS Appl. Polym. Mater. 2021, 3, 937-948. [CrossRef]

33. Lu, X.; Wang, C.; Wei, Y. One-dimensional composite nanomaterials: Synthesis by electrospinning and their applications. Small 2009, 5, 2349-2370. [CrossRef] [PubMed]

34. Ji, L.; Saquing, C.; Khan, S.A.; Zhang, X. Preparation and characterization of silica nanoparticulate-polyacrylonitrile composite and porous nanofibers. Nanotechnology 2008, 19, 085605. [CrossRef] [PubMed]

35. Liu, G.Q.; Jin, Z.G.; Liu, X.X.; Wang, T.; Liu, Z.F. Anatase TiO2 porous thin films prepared by sol-gel method using CTAB surfactant. J. Sol.-Gel. Sci. Technol. 2007, 41, 49-55. [CrossRef]

36. Hung, C.H.; Leung, W.W.F. Filtration of nano-aerosol using nanofiber filter under low Peclet number and transitional flow regime. Sep. Purif. Technol. 2011, 79, 34-42. [CrossRef] 